\title{
Questes
}

\section{La prophétie : conclusion}

\section{Maria Valeria Ingegno}

\section{OpenEdition}

Journals

Édition électronique

URL : http://journals.openedition.org/questes/3474

DOI : 10.4000/questes.3474

ISSN : 2109-9472

\section{Éditeur}

Les Amis de Questes

\section{Édition imprimée}

Date de publication : 15 juin 2014

Pagination : 121-124

ISSN : 2102-7188

\section{Référence électronique}

Maria Valeria Ingegno, «La prophétie : conclusion », Questes [En ligne], 28 | 2014, mis en ligne le 15 juin 2014, consulté le 15 septembre 2020. URL : http://journals.openedition.org/questes/3474 


\title{
Conclusion
}

\author{
Maria Valeria INGEGNO \\ Pontificia Università Gregoriana - E.P.H.E
}

Les contributions présentées dans cette revue s'intéressent à la prophétie non seulement sous un angle théorique, propre au commentaire biblique, mais aussi fabuleux, plus caractéristique des textes littéraires. Dans sa contribution, Maria Valeria Ingegno envisage la prophétie telle qu'elle est présentée dans trois commentaires de la $\mathrm{I}^{\text {ère }}$ Épître aux Corinthiens, rédigés entre le $\mathrm{XI}^{\mathrm{e}}$ et le $\mathrm{XII}^{\mathrm{e}}$ siècles. Le premier texte, celui de la Glossa d'Anselme et Raoul de Laon, montre que le charisme de la prophétie est ramené à l'activité de la mens, essentiellement destinée à exposer les vérités morales comprises dans le Nouveau Testament. Par ailleurs il apparaît, à la lecture de cet ouvrage, que le fait de prophétiser est conçu dans un cadre institutionnel strict dont les femmes sont exclues. Le deuxième commentaire, celui de Jean de Poitiers, tout en se référant au premier, identifie, quant à lui, la charité et la prophétie avec la prédication. Il envisage ces notions dans une perspective d'ordre ecclésiologique et pose la prophétie en liaison avec une militia Christi qui prend surtout la forme d'une expositio Scripturarum. Le troisième texte, celui de l'Anonyme poitevin, considère la prophétie comme une forme de prédication - de façon plus systématique que le texte de Jean de Poitiers. Cependant le véritable apport de l'Anonyme est de concevoir la prophétie comme une forme d'exégèse : en effet, cet auteur présente les prophètes comme des interprètes des Écritures, qui par leur compréhension auront accès aux vérités morales. 
Dans son article, Arnaud Sibille s'intéresse aux différentes techniques oraculaires, antérieures au XII ${ }^{\mathrm{e}}$ siècle et pratiquées en Occident, avant d'examiner la fidélité de leurs représentations littéraires. Il envisage ainsi l'astrologie, l'arithmancie, l'oniromancie, la cléromancie, les pronostics, en montrant comment ces techniques se sont diversifiées et complexifiées, avec l'arrivée des textes arabes en Occident : on voit ainsi apparaître de nouvelles pratiques comme la chiromancie, la géomancie ou encore la physiognomonie. L'auteur souligne par ailleurs la simplification de ces pratiques dans la littérature médiévale, dans laquelle il est rare de trouver des précisions sur les techniques divinatoires, bien que certaines pratiques y soient détaillées. Citons, à titre d'exemple, un devin jetant de la paille d'une fenêtre (Moniage Guillaume), observant des étoiles ou interprétant un reflet dans un miroir ou dans l'eau d'une source (Fontaine amoureuse). Arnaud Sibille établit, enfin, qu'à côté des nigromants et des devins, les prophètes pratiquent eux aussi la prophétie qui à leur égard est perçue comme le signe d'une élection déterminée par la Providence.

Dans sa contribution, Loren Gonzalez envisage la prophétie telle qu'elle s'exprime à travers l'image du loup-prophète, dans l'Ysengrimus de Nivart de Gand et la Topographia Hibernica de Giraud de Barri. Ces textes, qui datent de la seconde moitié du XII siècle, sont fortement imprégnés de culture cléricale. Loren Gonzalez établit un parallèle entre ces deux types de prophétie, en relevant que la première est liée au thème de la malédiction et que la seconde prend la forme d'une interprétation de l'Histoire et de l'exégèse. Elle signale notamment que le loup - en tant qu'animal guide, doué d'une intelligence supérieure et familiarisé avec l'au-delà - peut incarner non seulement le faux prophète, mais aussi le vrai, parce qu'il peut convertir en vérité chrétienne le discours du faux prophète. Le loup apparait, dans les œuvres de Nivart de Gand et de Giraud de Barri, comme l'instrument privilégié tant de la parole prophétique que de la 
parole satirique : cet animal dénonce des réalités scabreuses, prenant parfois des positions anticléricales qui permettent d'apporter une image dédoublée de la réalité du clergé d'alors. Par conséquent, le personnage du loup a permis une fusion entre la fausse et la vraie prophétie ainsi qu'une prise de conscience du caractère subversif propre à la parole prophétique, qui se caractérise comme une forme de savoir aux traits mystérieux, insaisissable.

Camille Rouxpetel s'intéresse dans son étude à la figure mystérieuse et charismatique du Prêtre Jean, produit du programme de Réforme de l'Église du XII ${ }^{\mathrm{e}}$ siècle. Comme figure du roi sauveur, typique de la fin des temps et propre aux apocalypses médiévales, le Prêtre Jean, par son exemplarité, se caractérise par son lien avec Jérusalem et par son dévouement à la cause de l'Église en Terre sainte. Aussi la prophétie estelle représentée à l'aide d'un souverain, perçu comme providentiel, qui incarne efficacement les inquiétudes et le sens de la précarité vécus par les Latins d'Orient. Le Prêtre Jean apparaît donc comme le protagoniste d'une prophétie qui annonce d'une part la victoire du christianisme sur la mécréance et le paganisme, et d'autre part la représentation d'un Orient mystérieux certes, mais aussi christianisé et idéalisé. La prophétie se présente alors comme une raison de rencontre non seulement entre l'Orient et l'Occident mais aussi entre les milieux nestoriens arabophones et les représentations religieuses et culturelles caractéristiques des Latins de Terre sainte.

Ces contributions relatives à la prophétie offrent une grande variété de sujets ainsi que de nombreuses réflexions tant morales qu'ecclésiologiques, anticléricales, eschatologiques ou idéalisantes. Des textes en langues latine et vernaculaire s'y entremêlent, démontrant ainsi que la prophétie intéresse tous les domaines du savoir et de la production 
textuelle: la diversité des sources étudiées s'allie à l'originalité des perspectives envisagées par leurs auteurs. 